\title{
Gênero e montagem em Os óculos do vovô (Francisco Santos, I 9 |3): anotações de um historiador
}

\author{
Eduardo Morettin'
}

\begin{abstract}
Resumo
O objetivo do artigo é analisar as relações entre cinema e história a partir de Os óculos do vovô (Francisco Santos, 1913), o mais antigo remanescente da produção ficcional da história do cinema brasileiro. Serão examinados o diálogo da obra com o seu contexto histórico e as questões de estilo, como a estratégia de montagem. Inspirado pelo texto Jogo de Armar: anotações de catalogador, de Maria Rita Galvão, os apontamentos da historiadora em relação à obra também serão objeto de reflexão.
\end{abstract}

Palavras-chave:

Cinema e história; História do cinema brasileiro; Preservação audiovisual.

\begin{abstract}
The purpose of this article is to analyse the relations between cinema and history from Os óculos do vovô (Francisco Santos, 1913), the oldest remnant of fictional production in the history of Brazilian cinema. We will examine the dialogue of this work with its historical context and style aspects, such as the editing strategy. Inspired by the text Jogo de Armar: anotações de catalogador, by Maria Rita Galvão, her historical notes regarding the work will also be the object of reflection.
\end{abstract}

\section{Keywords}

Film and History; Brazilian Film History;Audiovisual Preservation

Os óculos do vovô (1913), de Francisco Santos, realizado na cidade de Pelotas, estado do Rio Grande do Sul, é o mais antigo filme de ficção remanescente da história do cinema brasileiro ${ }^{2}$. Os "posados", como se chamavam no Brasil produções como a de Santos, eram exceção dentro do quadro geral, sendo a "continuidade do cinema brasileiro assegurada quase exclusivamente pelo documental”, como salientou Paulo Emilio Salles Gomes (1986, p. 324). Não é minha intenção aqui, ao recuperar Os óculos do vovô, sobrevalorizar esse tipo de produção, em alinhamento com o que Jean-Claude Bernardet afirmou ser a vontade tanto de pesquisadores quanto de cineastas de projetar sobre o passado uma linearidade cujo sentido desembocava na própria afirmação de um cinema em busca de seu público (1995, p. 25 e ss). Meu interesse é indicar os caminhos possíveis para pensar as conexões entre a pesquisa histórica e a análise estética, por meio do diálogo do filme com o seu contexto mais imediato e com a produção cinematográfica da época a fim de apontar suas especificidades. De Os óculos do vovô sobreviveu menos de um terço de sua duração original de

\footnotetext{
I Professor da Universidade de São Paulo e autor de Humberto Mauro, Cinema, História (SP, Alameda Editorial, 2013). Organizou, dentre outros trabalhos, $O$ cinema e as ditaduras militares: contextos, memórias e representações audiovisuais (São Paulo, Intermeios, 2018). É bolsista produtividade em pesquisa CNPq, nível 2, e membro do Conselho da Cinemateca Brasileira desde 2007.

$2 O$ artigo se origina da conferência de abertura Genero y montaje en Los lentes del abuelo (Francisco Santos, 1913): anotaciones de un historiador, que proferi no III Coloquio de Estudios de Cine y Audiovisual Latinoamericano de Montevideo promovido pelo Grupo de Estudios Audiovisuales (GESTA), no Museo Nacional de Artes Visuales (MNAV), no dia 13 de setembro de 2018, Montevidéu, Uruguai.
} 
15 minutos, mais precisamente quatro minutos e dezesseis segundos ${ }^{3}$. Eis a sinopse disponível na sua ficha catalográfica da Cinemateca Brasileira:"O menino peralta pinta os óculos de seu avô enquanto este dorme. Ao acordar, o avô leva um susto, diante da cegueira imaginada, criando uma série de confusões dentro de casa" ${ }^{4}$.

Maria Rita Galvão, em texto que permaneceu praticamente inacessível durante muito tempo ${ }^{5}$, realizou no início dos anos noventa um meticuloso estudo ${ }^{6}$ comparativo das cópias existentes na Cinemateca do Museu de Arte Moderna do Rio de Janeiro e na Cinemateca Brasileira, esta oriunda da antiga Empresa Brasileira de Filmes (Embrafilme), auxiliada pelo exame de documentação textual e iconográfica. A intenção maior da autora era demonstrar a importância,"para o desenvolvimento dos estudos universitários de História do Cinema, (d)o trabalho de preservação, documentação e catalogação das cinematecas" (2018a, p. 169). Trata-se provavelmente do primeiro texto no Brasil a discutir de maneira detida o processo de restauração de um filme e as escolhas nele implicadas.

Não à toa, como Maria Rita Galvão fez questão de frisar, seu estudo se intitula Jogo de Armar e tem por complemento Anotações de catalogador, referência que se encontra presente no título de meu artigo.Trata-se de uma forma que encontro de homenagear a historiadora que há pouco nos deixou e de trazer a discussão, a partir da pequena mudança feita no subtítulo, para os domínios do cinema e da história, campo de conhecimento ao qual me dedico há certo tempo.

Inicio meu percurso pelos dados externos à obra, naquilo que se convencionou chamar de pesquisa histórica. Trago, portanto, alguns apontamentos sobre o diretor e a cidade de Pelotas. Como muitos dos cinegrafistas que se aventuravam pelo cinema, Francisco Santos era um imigrante de origem portuguesa, que chegou ao Brasil no início do século $X X^{7}$. Circulando pela região do Prata e por diversos estados do país com sua companhia teatral, estabeleceu-se no sul nos anos 1910, abandonando o teatro para se estabelecer em $1912 \mathrm{em}$ Pelotas e se dedicar aos filmes de ficção e documentários por cerca de dois

3 O filme está disponível em http://www.bcc.org.br/filmes/443/83, acesso 03/I I//8. Integra também a caixa de DVDs Resgate do Cinema Silencioso Brasileiro, vol. 4,Vida Cotidiana, edição da Cinemateca Brasileira e Sociedade de Amigos da Cinemateca, com apoio da Caixa Econômica Federal, 2009. Dos 27 títulos que compõem a caixa, Os óculos do vovô é a única ficção.

4 Disponível em http://bases.cinemateca.gov.br/cgi-bin/wxis.exe/iah/!lsisScript=iah/iah.xis\&base=FILMOG RAFIA\&lang=p\&nextAction=Ink\&exprSearch $=I D=001395 \&$ format $=$ detailed.pft\#I, acesso em 30/I0/2018. 5 Discorro sobre o texto e o trabalho de Maria Rita Galvão (MORETTIN, 2018) em dossiê que organizei em homenagem à historiadora publicado pela revista Vivomatografias (http://www.vivomatografias.com/) no final de 2018.

6 Do estudo foram originados três materiais: Os óculos do vovô (Francisco Santos, 2013). Descrição plano-a-plano (GALVÃO, 2018c); Jogo de Armar. Decupagem comentada de Os óculos do vovô (Francisco Santos, 2013) (GALVÃO, 20I8b); e um texto analítico sobre esse processo intitulado Jogo de Armar: anotações de um catalogador (GALVÃO, 2018a), que será comentado a seguir.

7 Todas as informaç̧̃es sobre Os óculos foram retiradas do referido estudo de Maria Rita Galvão (2018a) e Alice Trusz (2018). Para uma biografia do diretor e de suas atividades ver SANTOS; CALDAS, 1995 e PÓVOAS, 2009, p. 17 - 38. Glênio Póvoas (2009) noticia a exibição do filme em abril e maio de 1913 na cidade de Santa Maria (RS). 
anos. Essa trajetória, a de imigrantes que circulam pelo país com suas companhias teatrais rumo, muitas vezes, a Montevidéu e Buenos Aires, é similar a de diversos cineastas brasileiros, como o italiano Vittorio Capellaro, que no mesmo período se fixa no Brasil e dirige, em 1915 na cidade de São Paulo, Inocência.

Por que a escolha de Pelotas por Francisco Santos em dezembro de 1912 para iniciar sua atividade cinematográfica? De que maneira Os óculos do vovô se relaciona com o seu contexto mais imediato? Não é possível no espaço de um artigo fornecer todas as respostas para as duas perguntas, mas alguns elementos podem ser evocados.

Em primeiro lugar, Pelotas era um dos centros dinâmicos da economia do Rio Grande do Sul. Enriquecidas ao longo do século XIX pela exploração do charque, atividade econômica assentada no trabalho escravo, importante dizer, as elites locais celebravam em 1912 o centenário da cidade, valorizando tudo o que pudesse ser tomado como distintivo da modernidade pretendida, a fim de encontrar o seu lugar no panteão das urbes "civilizadas" ao lado dos grandes centros urbanos do país, em especial o Rio de Janeiro, então capital da Repúbli$\mathrm{ca}$, cidade modelo dessas transformações.

Dentre as inúmeras iniciativas dessa empreitada levada a cabo pelas elites, temos a Revista do Primeiro Centenário de Pelotas, projeto editorial coordenado por João Simões Lopes Neto, intelectual e escritor de prestígio da cidade e região, tendo circulado seus oito números entre outubro de $191 \mathrm{I}$ e maio de $1912^{8}$. O objetivo da publicação, conforme as palavras do autor, era o de reunir "os retratos e traço biográfico das individualidades de destaque como fator pensante, dirigente, responsável, da nossa vida urbana” (apud RUBIRA, 20I2, p. 37) ${ }^{9}$, e elencar o número de fábricas, oficinas, casas diversas de negócio em funcionamento, atestado do desenvolvimento econômico de Pelotas. Por mais que possamos duvidar do número - Lopes Neto chega a "I.288 firmas em atividade” - (apud RUBIRA, 20I2, p. 40), interessa ressaltar esse esforço, tão comum às elites de outras cidades do período, de construir simbolicamente um lugar de enunciação marcado pela pujança econômica e intelectual, conjugadas aqui não apenas pelas estatísticas, mas pela tentativa de demonstrar a existência de uma vida cultural que é tida como alicerce desse "progresso".

Não me parece desprovido de significado que Francisco Santos, ao se instalar em Pelotas, tenha dado ao seu empreendimento o pomposo nome de Fábrica de Fitas Cinematográficas Guarany, ainda mais se considerarmos a inexistência de uma indústria cinematográfica nacional e, consequentemente, a diminuta presença de nossos filmes nos cinemas. Por mais que a Fábrica tenha sido, como nos relata Alice Trusz, "o exemplo mais estruturado e dinâmico de uma produtora cinematográfica estabelecida no Rio Grande do Sul”, e tenha produzido em pouco mais de um ano quatro filmes de ficção e registros de caráter documental (TRUSZ, 20 I8), a atribuição desse nome, Fábrica, à empresa enfatiza a dimensão econômica de sua atividade, aspecto valorizado na Revista do Primeiro Centenário de Pelotas, como vimos ${ }^{10}$.

Ao mesmo tempo, sua iniciativa de instalar uma fábrica de filmes cor-

8 O fac-símile dessa revista se encontra em RUBIRA, 2012.

9 Gostaria deixar registrado meu agradecimento à Alice Trusz, que forneceu inúmeros materiais e referências sobre Francisco Santos e Pelotas.

10 Nada mais distante da realidade econômica do cinema brasileiro, sem recursos, sem apoio do Estado e sem presença no circuito exibidor, do que a denominação fábrica, pois o setor vivia de iniciativas isoladas e não era reconhecido como pelas elites atividade cultural relevante (GALVÃO, 1975). 
respondia aos anseios de uma elite interessada em demonstrar que também em sua cidade o cinema participava ativamente desse concerto pelo progresso. Não à toa, há, dentre as atividades programadas para julho de 1912, destinadas a celebrar o centenário de Pelotas, a realização de matinês em todas as salas de exibição (BORGES, 20I2, p. 73).

Desde 1909, com a inauguração do Éden Salão, a cidade contava com um circuito exibidor próprio, sendo recente o hábito de assistir filmes às tardes. De acordo com Klécio Santos, nesse período as produções da Pathé, Gaumont e Nordisk "passaram a inundar Pelotas" (20I4, p. I96), contribuindo para diminuir a afluência do público ao teatro. Victor Russomano, em Cinematographo, artigo escrito para o jornal Opinião Pública sediado em Pelotas, em 22 de fevereiro de 1913, ano em que Francisco Santos realiza Os óculos do vovô, comentava:

\section{É possível apreciar trabalhos [no cinema] que, na cena do teatro, nos custariam os olhos da cara! faz bem ou mal o povo, preferindo- $-0 ? . .$. O que nos interessa saber que ele vai aos espetáculos cine- matográficos, deixando às moscas os teatros caríssimos..." (apud SANTOS, 20I4, p. 196).}

Francisco Santos, ao instalar sua fábrica na cidade, não só continuou com a atividade teatral, ao contrário do que poderíamos supor a partir do diagnóstico de Russomano, como diversificou os seus investimentos, articulados em torno da produção cultural.

Em abril de 1913 arrendou o Coliseu de Pelotas, "um galpão com capacidade para 1.800 pessoas", oportunidade "para retomar como produtor suas atividades teatrais e criar a Companhia Cidade de Pelotas, com um elenco formado por alguns dos atores de seus filmes, como os irmãos Pêra e Graziella Diniz" (SANTOS, 2014, p. 197). Em setembro de 1914, logo após o término de sua fábrica de filmes, foi o responsável pelo "retorno das peças teatrais de Simões Lopes Neto aos palcos", reencenando a opereta Os Bacharéis, a partir de uma "série de reivindicações (do autor), todas atendidas" pelo diretor (SANTOS, 20 I4, p. 197). A opereta será no mesmo ano publicada por Francisco Santos, que havia fundado com Vieira Xavier, em 1913, a Tipografia Guarany, ou, como se chamava à época, a OficinaTipográfica da Fábrica Guarany.

Santos, nesses anos, tornou-se um bem sucedido empresário do setor cultural, associando-se a figuras-chave do meio intelectual, como atesta a ligação com Lopes Neto. Para mim, esse vínculo com as elites e a sintonia com o discurso construído no centenário estão presentes no filme.

Nas poucas imagens em que vemos a rua em Os óculos do vovô, o ponto de vista adotado pela câmera valoriza o espaço organizado da cidade, presente no padrão existente de suas casas, ruas e calçamento, na iluminação pública, em tudo o que é indício de intervenção da engenharia e arquitetura no planejamento urbano, como podemos ver na figura I"I.

II As imagens de Os óculos do vovô utilizadas nesse artigo foram retiradas do Banco de Conteúdos Culturais (disponível em http://www.bcc.org.br/filmes/443/83, acesso em 02/I I/2018). 


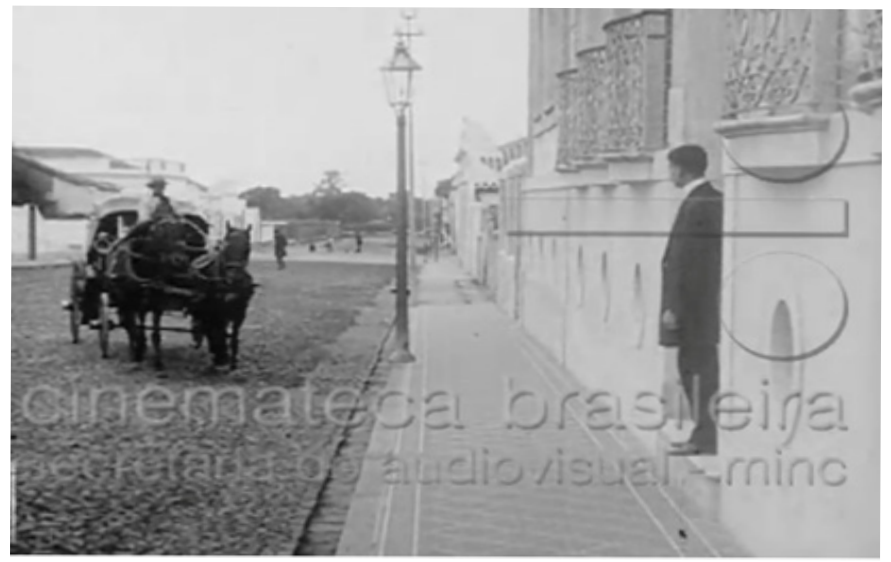

Figura I

A residência que vemos no filme, aliás, pertencia a Francisco Santos e era sede de sua fábrica. Ela se localizava na esquina da rua Marechal Deodoro com a rua General Telles, um dos eixos centrais da planificada cidade, como vemos na planta abaixo (figura 2$)^{12}$.

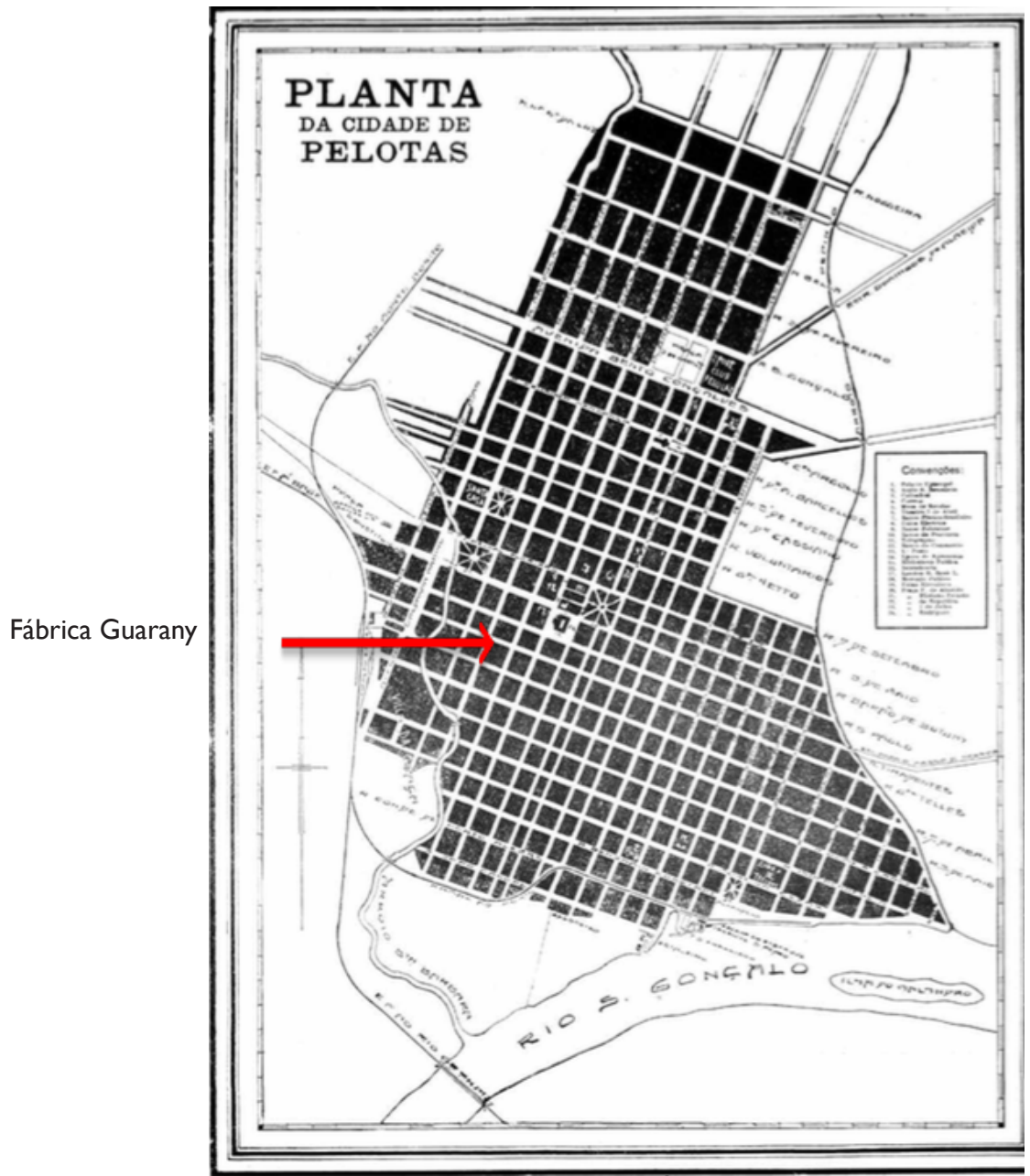

Figura 2

12 Planta da Cidade de Pelotas, 1922. Publicada no "Álbum de Pelotas no Centenário da Independência (I822-1922)", de Clodomiro C. Carriconde. Retirada de RUBIRA, 20I4, p. 10. 
A edificação havia sido a residência de um dos sócios do Moinho Pelotense, sinal de que os negócios de Francisco Santos iam bem e de que chegou a Pelotas com capital significativo para dar início às suas atividades. Em registro fotográfico feito nos anos 1900 (figura 3), vemos outro ângulo da casa, que nos fornece a sua exata dimensão ${ }^{13}$.
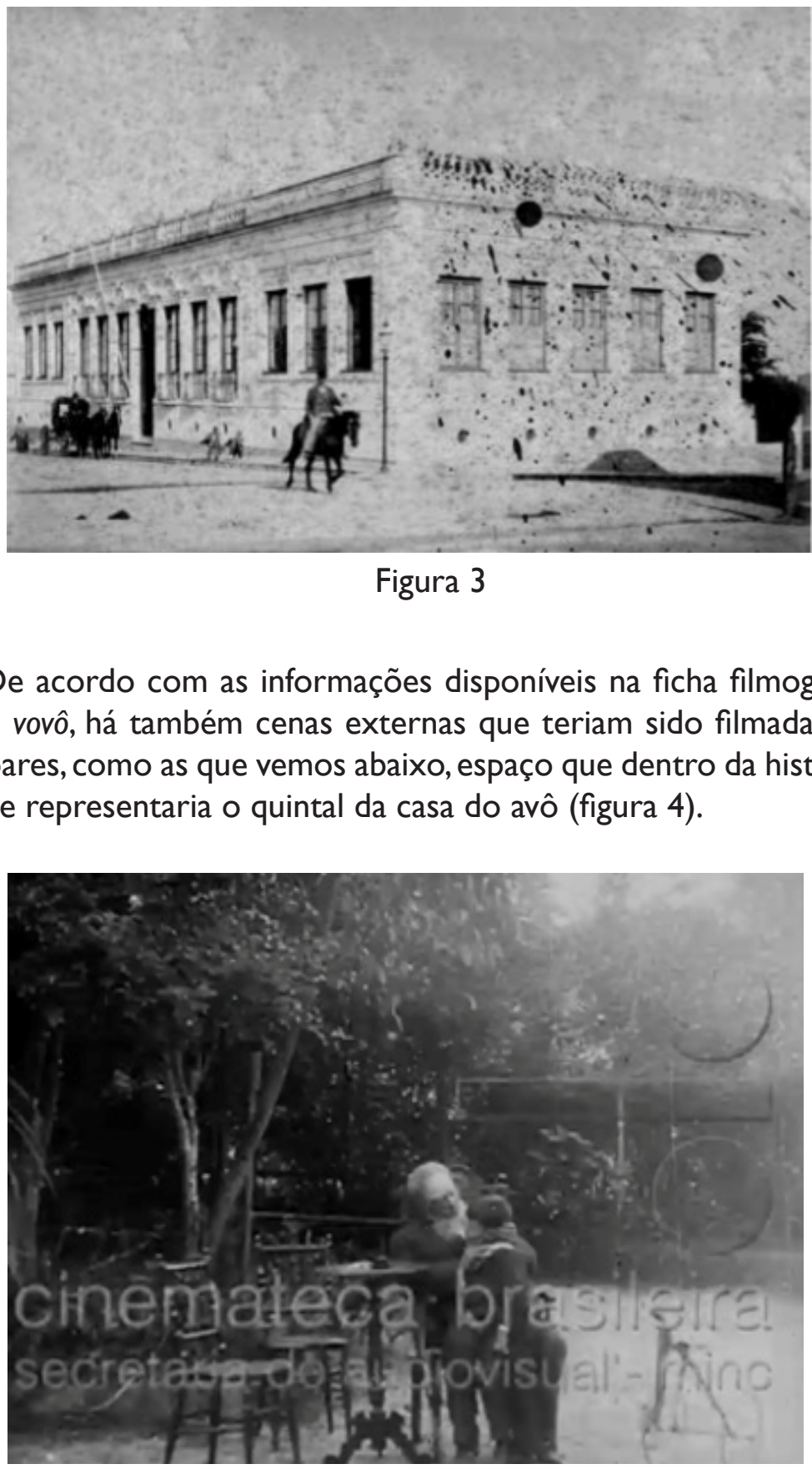

Figura 4

A escolha deste parque também não é casual, dado que se trata do espaço de lazer das elites à época (RUBIRA, 20।4, p. 2I8), como vemos na imagem a seguir (figura 5), que registra na década de 1900 o tipo de sociabilidade desejada nos jardins e parques da cidade.

I3 Rua Marechal Deodoro, esquina General Telles, imagem retirada de RUBIRA, 20 I2, p. 28I. As informações sobre a iconografia da cidade se encontram em ALMEIDA, 2012, p. 301 - 334. 


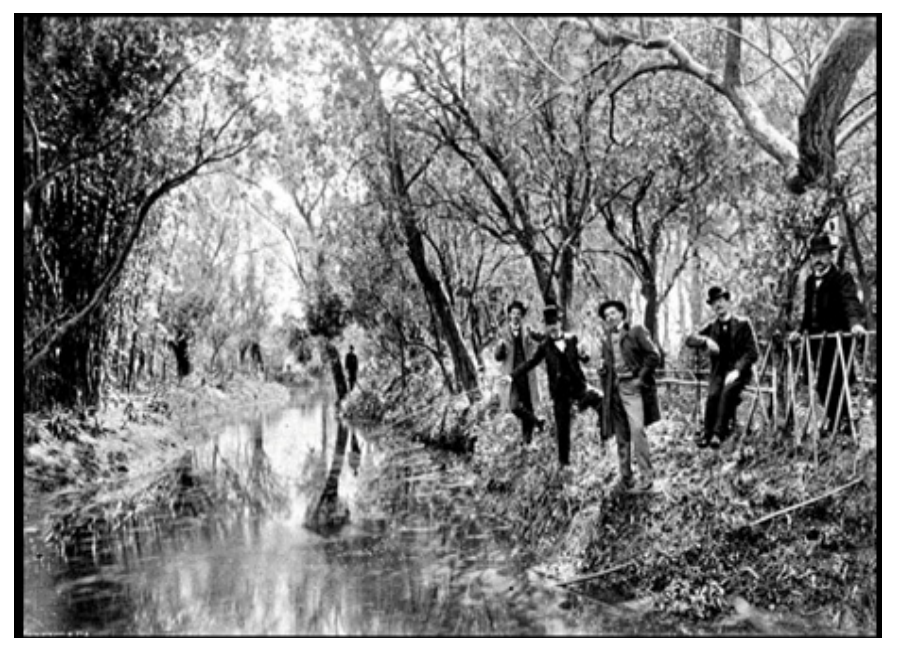

Figura 5

Deve-se notar que esse projeto de modernização não era advogado apenas pelas elites locais. Participava de um projeto mais amplo, como atesta a publicação em Barcelona, no ano de 1916, do livro $O$ Estado do Rio Grande do Sul, com quase 600 páginas dedicadas a fazer propaganda da região ao chamado mundo civilizado, alcance que se pretendia atingir com a sua tradução para o francês no mesmo ano.

Nesta publicação, o interesse das ilustrações selecionadas e dos textos que as acompanhavam residia em celebrar as cidades do estado como espaço de afirmação da modernidade, com destaque para os teatros, livrarias, cafés, jornais e edifícios públicos identificados com o progresso e bom gosto burguês ${ }^{14}$. No caso de Pelotas, além de políticos, artistas e intelectuais, uma imagem, de acordo com Luís Rubira, que teve acesso ao livro, nos traz "o retrato de um médico da cidade" (20I4, p. I8), sinal de que faltava ao elenco das autoridades tidas como responsáveis pelo ordenamento do espaço urbano aquela vista como competente para discorrer sobre os males que poderiam afetar o corpo social, recuperando aqui imaginário associado ao discurso sanitarista tão em voga naqueles anos.

Assim, parece-me significativo que na pequena história contada por Santos abra-se espaço para a presença de um médico (figura 6)

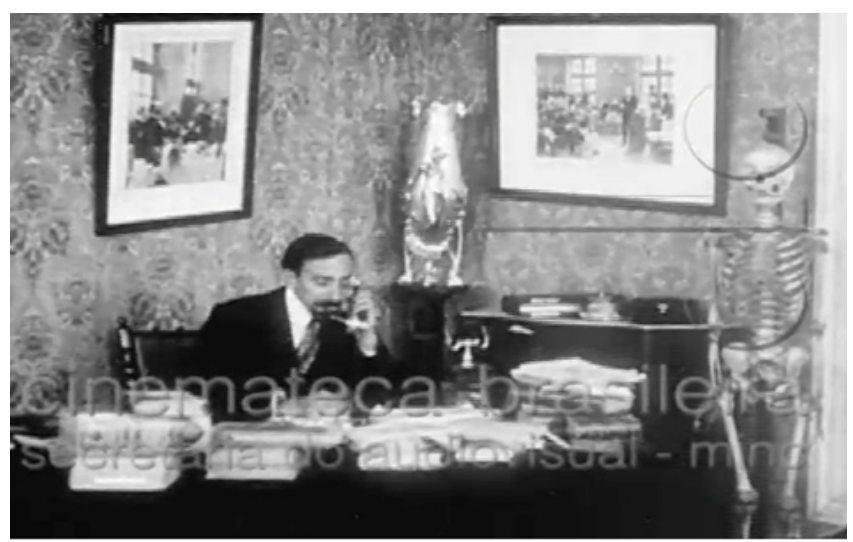

Figura 6

14 O cinema, de acordo com o relato de Luís Rubira (2014), não participa à época desse concerto burguês. 
Por mais que o registro do filme seja o cômico, como comentarei mais à frente, $o$ que justifica certas escolhas do cenário, como percebemos ao ver o esqueleto à nossa direita, o filme confere a ele destaque. Ao telefone, outro elemento distintivo, em escritório adornado com mobiliário elegante, percebemos que se trata de um estudioso, como as pilhas de livro em sua mesa parecem indicar

Com isso, ao terminar parte do percurso aqui trilhado, dedicado a estabelecer as conexões possíveis com o contexto mais imediato de produção de Os óculos do vovô, é possível concluir que Francisco Santos e sua obra constituem, portanto, um dos vetores desse discurso de valorização da modernidade de Pelotas.

Se a pesquisa histórica é importante para situarmos o filme e entendermos certas escolhas, principalmente no que diz respeito à presença de determinados temas e iconografia, acredito que a análise fílmica precisa ser enfrentada a fim de que possamos estabelecer o lugar dessa obra em sua história, história que é lacunar porque as obras não sobreviveram ${ }^{15}$.

A atividade da produtora de Francisco Santos é interrompida em 1914, com a escassez de filme virgem em virtude da Primeira Guerra Mundial, hipótese de Maria Rita Galvão (20I8a, p. I70) que é contestada por Alice Trusz (20I8). Desta produção restaram, como disse, os fragmentos de Os óculos, que pela sinopse transcrita atrás, tratar-se-ia de uma comédia. $\bigcirc$ condicional se deve ao fato de que não sobreviveram os planos da peraltice da criança e, muito menos, das confusões praticadas pelo vovô, o que dificulta a análise de sua inserção no gênero.

Carlos Roberto de Souza, em Riso Amargo, termina seu pequeno comentário sobre o filme com uma pergunta: "Engraçado?". Nesse artigo, em que faz um panorama do gênero no cinema silencioso brasileiro, o autor avisa:"Refletir sobre o humor no cinema brasileiro dos primeiros tempos (...) demanda exercício de arqueologia cinematográfica eivado de amargura". Um dos motivos dessa amargura é a "absoluta inexistência dos filmes", o que inviabiliza qualquer exame de ordem estética nesse diálogo com os gêneros (2012, p. 15). Por essa razão, nossa atenção deve se voltar a outros aspectos.

Como sabemos, até os anos 1970 o cinema produzido no final do século XIX e início do século $X X$ era antes conhecido como pré-cinema ou cinema primitivo, dada a percepção de que existia uma lacuna a ser preenchida, uma ausência daquilo que se configurou mais à frente, nos anos 1910, como cinema narrativo clássico ${ }^{16}$. No que diz respeito ao cinema brasileiro do mesmo período, as considerações de um historiador do porte de Paulo Emilio Salles Gomes, observa Maria Rita Galvão, iam no mesmo sentido. A partir das informações textuais colhidas em jornais e revistas, das fotografias remanescentes e do contato com Os óculos, Paulo Emilio generaliza: são "decalques canhestros do que se fazia nas metrópoles", de "pouca habilidade com que era manuseado o instrumental estrangeiro" e "tecnicamente muito inferiores ao similar importado". Enfim, uma "situação medíocre"17.

I5 Para quem se debruça sobre a história do cinema silencioso brasileiro, uma constatação pesarosa: neste período, menos de $10 \%$ dos filmes produzidos sobreviveu (SOUZA, 20I I, p. 17).

16 Sobre essas questões ver COSTA, 1995

17 Maria Rita Galvão cita (2018a, p. 175-176) trechos de dois textos de Paulo Emilio:"Pequeno cinema antigo" (1980 [1969]) e "Cinema: trajetória no subdesenvolvimento" (I 980 [1973]). Devemos considerar em seu caso, o caráter de intervenção do ensaio de 1973, esforço de síntese que alinhava toda a experiên- 
Da comparação entre as versões existentes ${ }^{18}$, Galvão se interessa por um plano intermediário, o de número 22 , com duração de 15 segundos, que vemos a seguir (figuras 7, 8, 9 e I0) (GALVÃO, 20I8a, p. I7I e ss.).

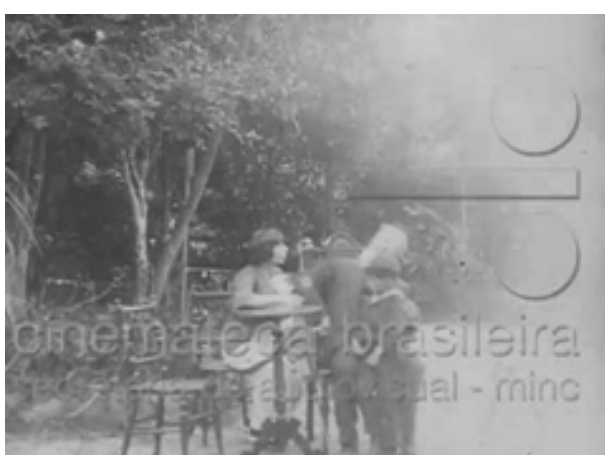

Figura 7

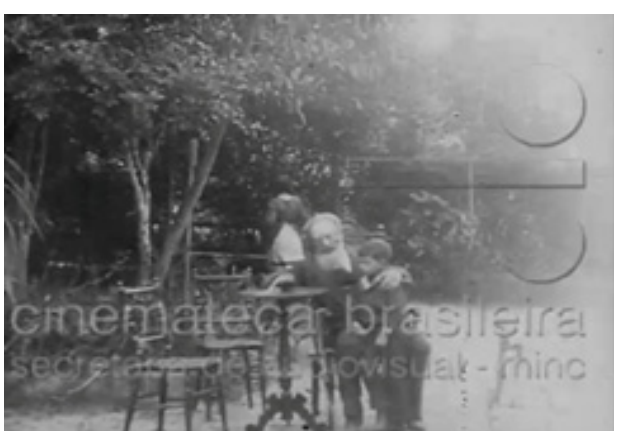

Figura 9

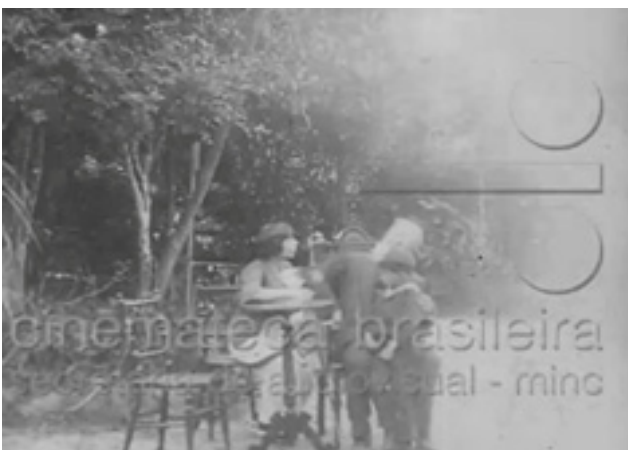

Figura 8

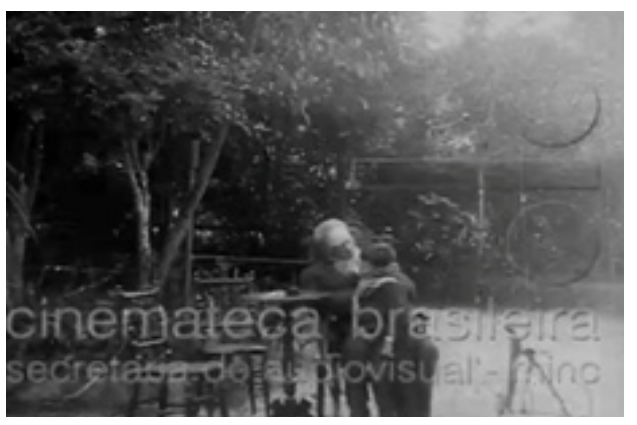

Figura 10

Como se pode observar, a mãe da criança peralta se levanta e parte em direção ao fundo do plano, deixando sozinhos o avô e seu neto. Esse plano está inserido logo após o momento em que o marido liga para o médico, pedindo-lhe que faça uma consulta em casa, pois o avô reclama que não está enxergando bem, e antes da sua chegada, quando de sua recepção pelo marido (figura I).

A divisão em blocos narrativos - são três, em acordo com a análise de Maria Rita Galvão (GALVÃO, 20I8a, p. I76) -, confere a esse plano uma função de continuidade, garantindo o "enquanto isso" típico da montagem paralela griffithiana, em sintonia com o que à época se fazia no cinema norte-americano. Haveria uma espera, dado que entre o término da ligação e a chegada do médico, é preciso que um certo tempo transcorra para que a ação seja crível.

Além do paralelismo, o uso fluído do campo e contracampo, a adoção

cia do século, buscando as conexões que explicam esta oscilação entre floração e declínio da produção de filmes no país, apontando a contribuição específica de cada tendência do cinema brasileiro e as condições dentro das quais cumpriu o seu trajeto, preocupado menos em consagrar talentos do que em delinear processos, tendo em vista o balanço histórico. Para um estudo mais aprofundado dessas questões ver MORETTIN; XAVIER (20I5).

18 Essa comparação é realizada de forma mais detida em Jogo de Armar. Decupagem comentada de Os óculos do vovô (Franscisco Santos, 20I3) (GALVÃO, 20I8b). Nele, do lado direito da folha, temos a disposição, em linha vertical, dos fotogramas do filme. Do lado esquerdo, uma coluna indica a numeração das imagens. Em paralelo, estão colados em formato retangular pequenos comentários datilografados, recortados de Jogo de Armar: anotações de catalogador (2018a). Há setas e observações escritas à caneta, indicando a sequência dos fotogramas, sua numeração, etc. A partir da folha $n^{\circ} 2$ (GALVÃO, 20I8b, p. 190), mais uma coluna é adicionada e atribuídos dois nomes: "fotos MAM" e "fotos Embra". Nesse roteiro de trabalho, exaustivo, a historiadora procura justificar as decisões que devem ser tomadas em um eventual processo de reordenação do filme a fim de se chegar à versão mais próxima da exibida em 1913. 
de cenário menos estilizado, a disposição da câmera em ângulo que sugere ao espectador um espaço para além do visto, o controle pela montagem do tempo e os deslocamentos das personagens pelo espaços cênicos atestam o domínio da continuidade tal como ela se configurou no cinema norte-americano do período.

O chamado plano 22 contestaria, assim, a suposição de que "a estrutura dos filmes brasileiros, até os anos 20 , era composta por uma sucessão de quadros de ação completa, interligados por letreiros que deveriam explicar os acontecimentos e estabelecer a concatenação lógica entre eles" (GALVÃO, 2018a, p. 174) $)^{19}$.

A historiadora observa que esses dados seriam "suficientes para revolucionar a ideia corrente sobre a construção da linguagem no cinema mudo brasileiro" (2018a, p. 186) ${ }^{20}$. Corroborando essa perspectiva, mas em caminho um pouco diferente, cabe destacar um elemento recorrente em Os óculos: o que Maria Rita Galvão chama de "o tempo de espera", que se evidencia em cada plano, em seu interior, com o registro de um antes e um depois da ação transcorrida. Não raro o plano permanece vazio, com a câmera captando o espaço cênico por onde as personagens circularão, como se ela estivesse à sua espreita (figuras II, I 2 e I3) ${ }^{21}$. Não há, portanto, nessas imagens ninguém à vista. Se há, trata-se de um envolvidos na história, no aguardo da chegada dos demais (figura 14).

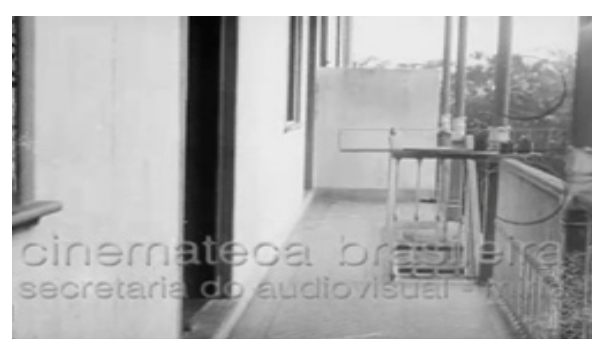

Figura II

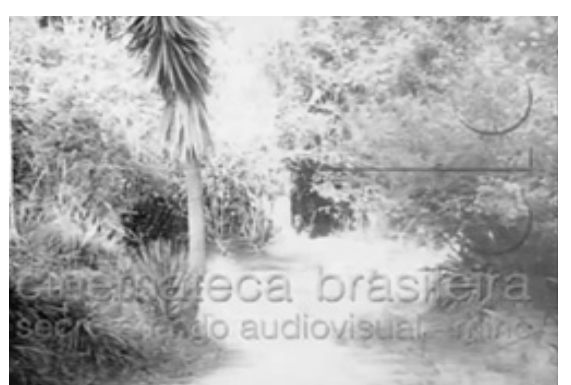

Figura 13

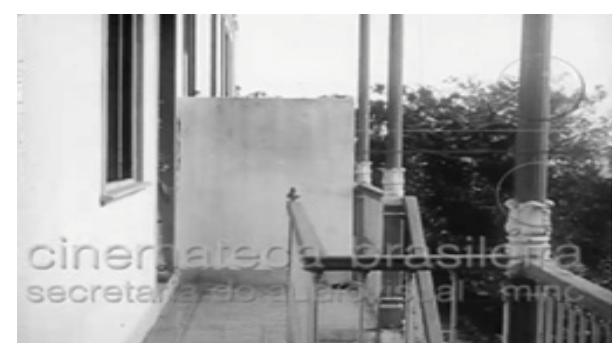

Figura 12

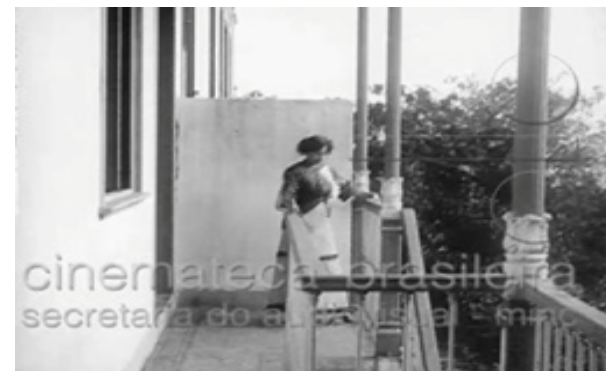

Figura 14

19 Um exemplo de filme pautado por essa estrutura seria, de acordo com Maria Rita Galvão (2018a, p. 174), o argentino La Revolución de Mayo (1909), de Mario Gallo, filme disponível para consulta em https:// www.youtube.com/watch?v=wZRG I25ovSc, acesso 03/04/2018. Andrea Cuarterolo (2017) analisa essa ficção e sua inserção no gênero filme histórico.

20 É importante frisar que o percurso realizado por Maria Rita Galvaão em seu estudo comparativo estabeleceu a versão que hoje conhecemos.

21 Apesar de similares, os fotogramas I e 2 pertencem a momentos diferentes do filme. Na versão disponível no Banco de Conteúdos Culturais, a primeira se encontra logo no início de Óculos, em 00:34, e a segunda em 4:05. 
Se Maria Rita Galvão indica os momentos em que há esse vazio e suspensão, ela não os explora em sua análise. Mesmo se tivermos no horizonte que a função dessa espera é sugerir ao espectador que outras ações transcorrem enquanto a câmera se detém em alguém ou em parte do cenário, fortalecendo o “enquanto isso", seu comentário sobre a figura I4 é revelador de que algo escapa à norma:"uma última vez temos ainda a varanda, e um tempo de espera, que é agora acintoso" (GALVÃO, 20 I8a, p. I85). Essa espera é marcada pela chegada da personagem da mãe à sacada (figura I5). Depois, ela se dirige ao parapeito e olha na direção de onde supostamente se encontram o médico e seu marido (figura 16). O plano acima (figura 14) corresponde ao momento em que ela se posiciona ao centro do quadro, dirigindo seu olhar no mesmo sentido.

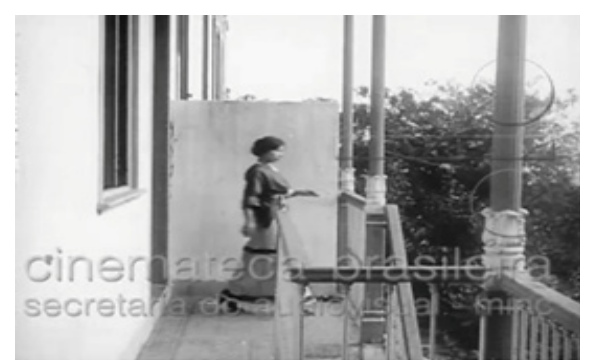

Figura I5

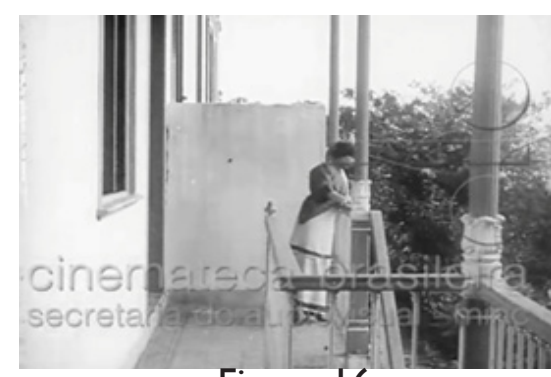

Figura 16

Um registro documental do mesmo ano realizado na cidade de São Paulo, Caça à Raposa (1913), de Antônio Campos, obra que já estudei em outro momento ${ }^{22}$, confirma a suposição de que a singularidade de Os óculos do vovô recai em outro aspecto. Como referido no próprio título, o pequeno filme trata da expedição organizada por Olívia Guedes Penteado nos campos do Barro Branco com os sócios da Sociedade Hípica Paulista, para a prática da "caça”. A associação era um clube de equitação das famílias abastadas de São Paulo, no qual poucos eram admitidos, sendo a elevada condição social garantia de passaporte de ingresso.

Se tomarmos como referência o cinema que se consolidou depois, à lá Griffith, esse documentário poderia ser considerado pouco articulado, com frouxa ligação entre os planos e com a ação estendida de forma desnecessária. A título de exemplo, acompanhamos o deslocamento da comitiva de "caçadores" do palacete Prates, residência de uma das mais abastadas famílias de São Paulo. A câmera se posiciona diante da mansão, e vemos passar diante da objetiva todo o cortejo, do primeiro cavaleiro ao último. Aos olhos acostumados com o cinema narrativo, teríamos carências. Devemos, porém, examinar a obra a partir de um ponto de vista que abrigue em seu campo a possibilidade de existir outros modos de construção estética, distintos de um referencial que estava por se erguer.

Neste sentido, duas considerações devem ser feitas. Em primeiro lugar, a aparente falta de continuidade de ação é substituída por um elemento que nos parece ser o centro efetivo das atenções: os indícios de riqueza, como o carro, os funcionários, o cavalo, as vestimentas de equitação e o pequeno círculo social identificado pela maneira de se portar e vestir. São estes os sinais que devem chamar a nossa atenção, antes de tudo, e este procedimento é estrutural dentro do filme.

22 Para um exame mais aprofundado desse filme e de seu contexto ver MORETTIN, 20I2, p. II - 43. 
Em segundo lugar, o documentário não está propriamente preocupado com as chamadas "peripécias da caçada", como definido pelo letreiro. Em três planos gerais, que se repetem do ponto de vista de sua composição, temos: um espaço situado no campo, sem a presença de ninguém; da direita para a esquerda ingressam na imagem uma amazona seguida pelo restante da comitiva, que vemos passar diante da câmera em sua quase totalidade. Não há, portanto, nem "peripécias", nem "caçada" ${ }^{23}$.

O filme é um exemplo tardio do gênero de filmes de perseguição, muito populares entre 1903 e 1906 (COSTA, 1995). Neles observamos o desenrolar de uma persecução em vários planos, constituindo o deslocamento das "personagens" o interesse central da obra. Em um primeiro momento, observamos a razão da fuga. A seguir, acompanhamos a tentativa de escapar, impedida pelas pessoas que partem em seu encalço. Com algumas variações, a estrutura de cada plano do filme se repete: plano geral ou de conjunto que nos mostra a paisagem ou o espaço a ser percorrido; o ingresso por um ponto distante em relação à câmera do fugitivo; os perseguidores em sua trilha; a passagem de todos em sua correria até o momento em que saiam do nosso campo de visão; por fim, o plano desprovido de figuras humanas, tal como no início. Não há corte no interior do plano e a ação é captada de seu início até o seu fim.

Talvez não fosse objetivo principal a busca de uma narratividade, construindo-se a sequência a partir do jogo perseguidor e perseguidos mais os obstáculos que se colocam entre os dois grupos. $O$ que talvez estivesse em jogo em Caça à Raposa ao mostrar todos os participantes nos planos mencionados fosse demonstrar o quanto os homens valorizavam a equitação como momento de reafirmação de sua posição social.

Em Os óculos a lógica do filme de perseguições prevalece, se considerarmos que, em um primeiro momento, é a mãe que sai em busca do menino travesso. Vemos o plano da sala, com o menino entrando ao fundo pela nossa direita (figura 17), imagem que corresponde ao plano da sequência inicial. A criança derruba o vaso (figura 18) e sai pela direita do quadro. Novo tempo de espera (figura 19), até o momento em que a mãe entra no espaço cinematográfico pelo fundo, à direita (figura 20), para sair no mesmo sentido do filho (figura $2 \mathrm{I}$ ) e deixar novamente a cena modificada apenas pela queda do vaso. Há espera também nas passagens em que as personagens se deslocam pelo espaço ou quando o avô e a mãe são deixados sozinhos no plano, como vimos acima.

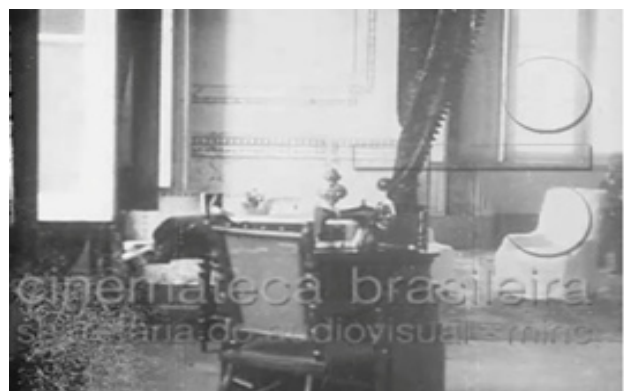

Figura 17

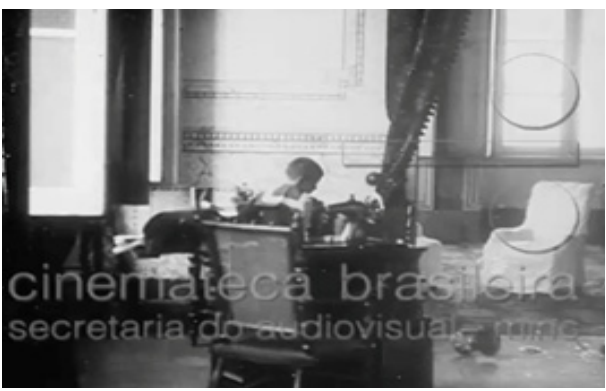

Figura 18

23 Não havia propriamente raposa, mas sim um cavaleiro habilidoso que partia na frente de todos e era o objeto da perseguição (MORETTIN, 20I2). 


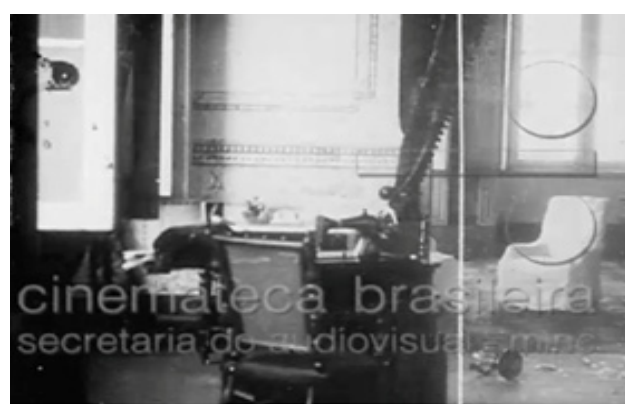

Figura 19

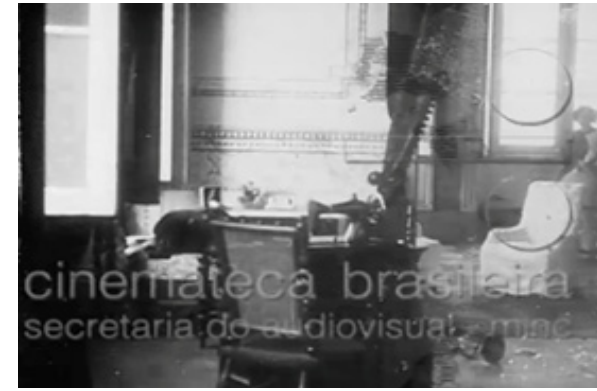

Figura 20

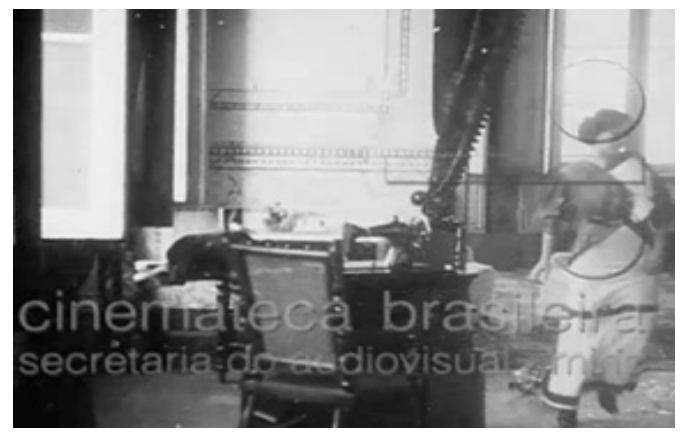

Figura 21

Curiosamente, nos momentos de maior identificação do filme com o que se fazia nos EUA, como no diálogo entre o médico (figura 6) e o pai da criança peralta, esse tempo aparentemente morto desaparece. Nesta sequência o telefone justifica a ligação entre espaços distintos em ação que transcorre simultaneamente, estratégia que é vista em muitas das realizações de Griffith para a produtora Biograph, como The Lonely Villa, lançado em julho de 1909, mas com uma finalidade diferente. No caso do diretor americano, o recurso geralmente é empregado nos momentos em que o suspense, criado pela pergunta "chegarão a tempo", é acentuado pelo corte rápido na sucessão de planos.

Em Os óculos do vovô não há suspense, e tudo flui na velocidade da informação expressa pelos diálogos travados ao telefone em um campo e contracampo. Tal agilidade, por sua vez, não se expressa de forma predominante na montagem do filme.

Curiosamente, como Alice Trusz observou, Francisco Santos tinha em sua trajetória teatral encenado peças dramáticas "de grande movimento, e onde há mortes, descarrilamentos, gritos, blasfêmias, todo o arsenal das peças congêneres, que são as melhores para chamar público ao teatro"(apudTRUSZ, 20I8)24.

Se a descrição desta peça nos remete aos sensational melodrama films, pouco dessa tradição se manteve nas imagens remanescentes de Os óculos do vovô. Há, portanto, no pequeno filme de 1913 a convivência de diferentes formas de articulação do tempo e de montagem: uma mais próxima ao cinema que se fazia à época e outra, como procurei apontar, que, contraditoriamente, esvazia o tempo da ação, dado que o interesse, ao que parece, é mostrar o desloca-

24 O comentário é de 1909 e foi publicado no jornal A Federação, de Porto Alegre, a propósito de Comboio n. 6, peça encenada por Santos naquele ano. 
mento das personagens pelos espaços mais do que a perseguição, aspecto que favorece a apresentação dos indícios de riqueza e modernidade tão caros às elites de sua época.

A similaridade desse arranjo temporal atestaria uma maneira singular de organização das imagens nesse contexto mais amplo de transição rumo ao que se tornou o cinema narrativo clássico? Dois anos antes de Nascimento de uma Nação, dois filmes, um posado, outro natural, realizados em regiões distantes no Brasil e diversas do ponto de vista cultural, sem que um realizador soubesse da existência do outro, apontariam a existência de uma tendência, de um modo específico de linguagem que se perdeu em meio à padronização subsequente?

Somente a descoberta de outros filmes e sua análise nos auxiliariam na resposta a essas questões, que demandam do pesquisador o conhecimento não apenas dos arquivos e seus documentos, mas das formas estéticas do cinema e de sua história.

\section{Referências}

ALMEIDA, Guilherme Pinto de. Notas introdutórias à iconografia do Almanaque do Bicentenário de Pelotas (Vol. I). In: RUBIRA, Luís (org.). Almanaque do Bicentenário de Pelotas. v. I. Santa Maria/RS: PRÓ-CULTURA RS / Gráfica e Editora Pallotti, 20I2, p. $30 \mathrm{I}-334$.

BERNARDET, Jean-Claude. Historiografia clássica do cinema brasileiro. Metodologia e pedagogia. São Paulo:Annablume, 1995.

BORGES, Luís. Revista do $1^{\circ}$ Centenário de Pelotas: uma visão retrospectiva e prospectiva. In: RUBIRA, Luís (org.). Almanaque do Bicentenário de Pelotas. v. I. Santa Maria/RS: PRÓ-CULTURA RS / Gráfica e Editora Pallotti, 20 I2, p. 69 - II 2. COSTA, Flávia Cesarino. O primeiro cinema. São Paulo, Scritta, 1995.

CUARTEROLO,Andrea."O cinema histórico argentino durante o período silencioso: dois modelos estéticos e ideológicos em disputa”. In: AGUIAR, Carolina e outros. Cinema e História: circularidades, arquivos e experiência estética. Porto Alegre, Editora Sulina, 2017, p. I19 - 159.

GALVÃO, Maria Rita. Crônica do cinema paulistano. São Paulo: Ática, 1975.

. "Jogo de Armar: Anotações de catalogador" . Vivomatografias. Revista de estudios sobre precine y cine silente en Latinoamérica. v. 4, n. 4, p. 167-I87, dic. 2018(a). Disponível em <http://www.vivomatografias.com/index.php/vmfs/ article/view/l89> Acesso em 30/0I/2019.

. “Jogo de armar. Decupagem comentada de Os óculos do vovô (Francisco Santos, 1913)". Vivomatografias. Revista de estudios sobre precine y cine silente en Latinoamérica. v. 4, n. 4, p. I88-2 I7, dic. 20 I8(b). Disponível em <http://www. vivomatografias.com/index.php/vmfs/article/view/|9|>, Acesso 30/0 I/2018.

. "Os óculos do vovô (Francisco Santos, 1913). Descrição plano-a-plano." Vivomatografias. Revista de estudios sobre precine y cine silente en Latinoamérica. v. 4, n. 4, p. 2I8-223, dic. 20 I8(c). Disponível em http://www.vivomatografias. com/index.php/vmfs/article/view/193, acesso 30/01/2019.

GOMES, Paulo Emilio Salles. A expressão social dos filmes documentais no cinema mudo brasileiro (1898 - 1930). In: CALIL, Carlos Augusto e MACHADO, Maria Teresa (orgs.). Paulo Emilio: um intelectual na linha de frente. São Paulo/Rio de Janeiro: Brasiliense/Embrafilme, 1986, p. 323 - 330.

. Cinema: trajetória no subdesenvolvimento. In: Cinema: trajetória no 
subdesenvolvimento. São Paulo, Paz e Terra/Embrafilme, 1980 [1973], p. 67 - 87. . Pequeno Cinema Antigo. In: Cinema: trajetória no subdesenvolvimento.

São Paulo, Paz e Terra/Embrafilme, 1980 [1969], p. II - 24.

MORETTIN, Eduardo. Dimensões históricas do documentário brasileiro no período silencioso. In: MORETTIN, Eduardo; NAPOLITANO, Marcos; KORNIS, Mônica (org.). História e Documentário. Rio de Janeiro, Editora FGV, 20I2, p. II -43 .

."Maria Rita Galvão, historiadora”. Vivomatografias. Revista de estudos sobre precine y cine silente en Latinoamérica. Vol. 4, n. 4, p. I55 - 166, dic. 2018. Disponível em http://www.vivomatografias.com/index.php/vmfs/article/ view/187, acesso em 30/01/2019.

; XAVIER, Ismail.“La critique cinématographique au Brésil et la question du sous-développement économique: du cinéma muet aux années 1970. I895.” Revue d'histoire du cinéma. Paris, n. 77, p. 9 - 3I, hiver 2015.

PÓVOAS, Glênio. "Confusões, entraves, desafios na história da Fábrica Guarany”. In: GUTFREIND, Cristiane Freitas; GERBASE, Carlos (orgs.). Cinema gaúcho: diversidades e inovações. Porto Alegre: Sulina, 2009, p. 17 - 38.

RUBIRA, Luís. “Apresentação.” Almanaque do Bicentenário de Pelotas (vol. I). In: RUBIRA, Luís (org.). Almanaque do Bicentenário de Pelotas. v. I. Santa Maria/RS: PRÓ-CULTURA RS / Gráfica e Editora Pallotti, 20I2, p. 33 - 68.

RUBIRA, Luís (org.). Almanaque do Bicentenário de Pelotas. v. 2. Santa Maria/RS: PRÓ-CULTURA-RS Gráfica e Editora Pallotti, 2014.

SANTOS, Klécio. "O reino das sombras palcos, salões e o cinema em Pelotas (I896-1970”). In: RUBIRA, Luís (org.). Almanaque do Bicentenário de Pelotas. v. 2. Santa Maria/RS: PRÓ-CULTURA-RS Gráfica e Editora Pallotti, 20I4, p. I89 - 224. SANTOS, Yolanda Lhullier dos; CALDAS, Pedro Henrique. Francisco Santos. Pioneiro no cinema do Brasil. Pelotas, RS: Edições Semeador, 1995.

SOUZA, Carlos Roberto. "Estratégias de sobrevivência”. In: PAIVA, Samuel e SCHVARZMAN, Sheila (orgs). Viagem ao cinema silencioso do Brasil. Rio de Janeiro: Beco do Azougue, 201 I, p. 14 - 28.

."Riso amargo". Recine, v. 9, n. 9, p. 14 - 19, dez. 2012

TRUSZ, Alice. "A produção cinematográfica no Rio Grande do Sul (I896 1915)”. In: In: RAMOS, Fernão e SCHVARZMAN, Sheila (orgs.). Nova história do cinema brasileiro. Vol. I. São Paulo, Edições Sesc São Paulo, 20 I 8, p. 52 - 89. 